12 COVID REALITIES: PIVOTING TO VIRTUAL QI TRAINING IN INDIA

${ }^{1}$ Poonam Gupta, ${ }^{2}$ Marie Schall. ' Hamad Medical Corporation; ${ }^{2}$ Institute for Healthcare Improvement

\subsection{6/bmjoq-2021-IHI.12}

Abstract Description A program to scale-up improvements in maternal and newborn health in India confronted the challenges of providing quality improvement training to leaders and front-line clinicians and staff in 38 district hospitals in the state of Bihar, India. Virtual training programs, while not entirely new to the participants, was something that had not been done before on this scale. Results showed exciting improvements in quality improvement understanding and skills, as well as confidence to use and apply new-found knowledge.

\section{A LEARNING SYSTEM FOR SAFER RE-OPENING OF K-12 SCHOOLS DURING THE COVID-19 PANDEMIC}

Moira Inkelas, Vladimir Manuel. University of California, Los Angeles Clinical and Translational Science Institute, USA

\subsection{6/bmjoq-2021-IHI.13}

Background School closures due to the coronavirus disease 2019 (COVID-19) pandemic are harmful to children's education. Uncertainty in infectiousness and challenges of managing

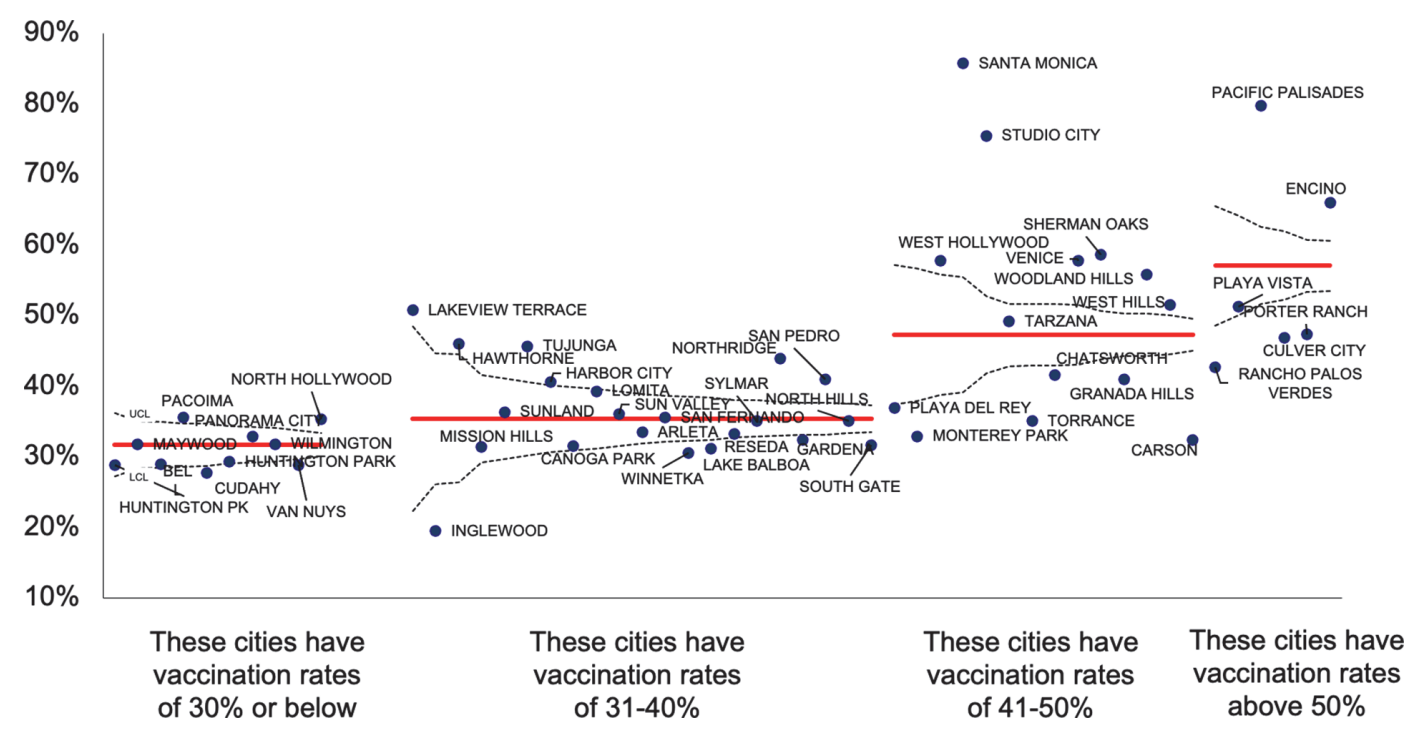

Abstract 13 Figure 1 P Chart (funnel chart):\% of Los Angeles Unified elementary students electing in-person learning by city within the school district catchment area when schools re-opened, stratified by community vaccination rate

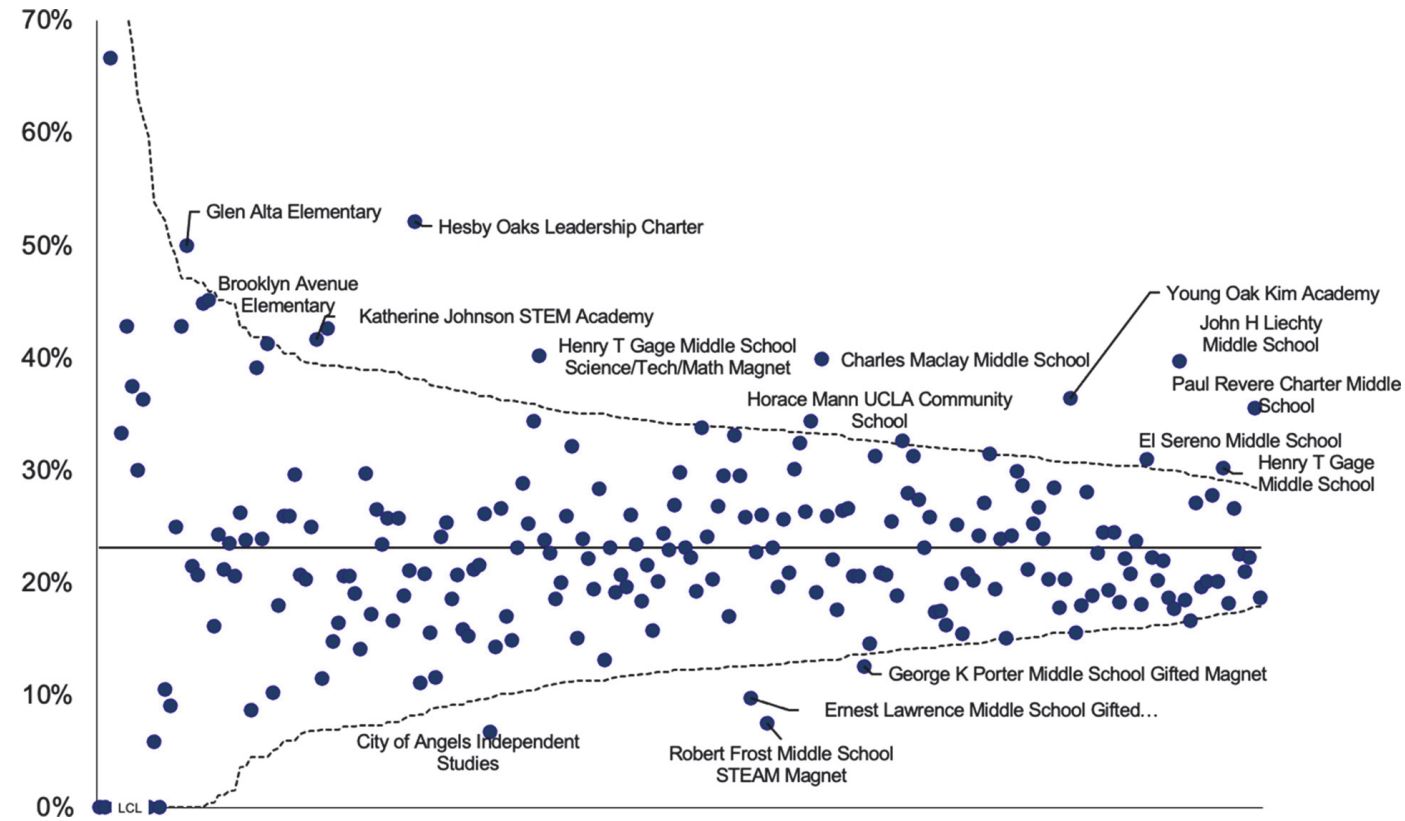

Abstract 13 Figure $2 \quad P$ Chart:\% of Grade 6-8 students electing in-person learning in 215 middle schools 